REVIEW

\title{
Vitamin A and preterm infants: what we know, what we don't know, and what we need to know
}

\author{
H Mactier, L T Weaver
}

Arch Dis Child Fetal Neonatal Ed 2005;90:F103-F108. doi: 10.1136/adc.2004.057547

Vitamin $A$ is essential for optimal growth and development. In the developing world, vitamin A supplementation of the newborn infant reduces mortality. In the developed world, extremely preterm infants are born with low body stores of vitamin $A$ and are at high risk of vitamin A deficiency. Optimal vitamin A supplementation for this population is not clearly defined, however, and, despite evidence of benefit, early vitamin A supplementation of extremely preterm infants is not uniformly practised in the United Kingdom. There is an urgent need for studies in preterm infants that include quantification of hepatic stores and functional assessment of vitamin A status as well as long term outcome.

See end of article for authors' affiliations

Correspondence to:

Dr Mactier, Neonatal Unit, Princess Royal Maternity, 8-16 Alexandra Parade, Glasgow G31 2ER,

Scotland, UK;

helen.mactier@

northglasgow.scot.nhs.uk

Accepted 25 August 2004
$\mathrm{V}$ itamin A is one of the most important micronutrients affecting the health of children. Recognised for nearly 90 years as an essential dietary constituent, it is necessary for orderly growth and differentiation of tissues. $^{12}$ In the developing world, vitamin A supplementation programmes significantly reduce infant mortality as well as the incidence of xerophthalmia, respiratory infection, and morbidity from gastrointestinal disease. ${ }^{3-5}$ Supplementing newborn infants with vitamin A within 48 hours of birth reduces infant mortality by almost a quarter, with the greatest benefit to those of low birth weight. ${ }^{6}$ The World Bank estimates that vitamin A supplementation is one of the most cost effective health interventions available. ${ }^{7}$ In the developed world, most infants and children are vitamin A sufficient. Term infants are well supplied with vitamin A in utero (at the expense of maternal stores), and both human milk and infant formulae contain adequate amounts of vitamin A for normal growth and health in the first six months. ${ }^{8}$ Clinical vitamin A deficiency occurs rarely, and almost exclusively in children with malabsorptive disorders.

\section{PRETERM BABIES}

Unfortunately, vitamin A sufficiency cannot be assumed for preterm infants. This important subgroup of our infant population is born with inadequate body stores of vitamin $\mathrm{A}$, is often unable to tolerate routine oral supplementation, and is prone to diseases of the eye and respiratory and gastrointestinal tracts. Preterm infants have low plasma concentrations of both retinol and retinol binding protein (RBP) at birth compared with term infants, ${ }^{9-12}$ and this reflects low hepatic stores. ${ }^{13-15}$ Plasma concentrations of retinol remain low during the infant's stay in the neonatal unit, and throughout the first year of life, ${ }^{11}{ }^{16} 17$ especially in preterm infants of multiple births. ${ }^{17}{ }^{18}$ These issues have been recognised for over 20 years. Yet preterm infants (particularly those of extremely low birth weight $(\mathrm{ELBW})$ ) remain at risk of vitamin A deficiency because neither is optimal intake known nor are methods to assess vitamin A status properly defined.

\section{UPTAKE AND METABOLISM OF VITAMIN A}

The term vitamin A refers to a group of compounds, including retinol, retinaldehyde, and retinoic acid. Retinol may be obtained directly from foods of animal origin or be formed in the body from metabolism of $\beta$-carotene. Absorption of dietary retinyl esters is complex, involving hydrolysis and complexation with bile acids in the gut lumen before uptake by enterocytes $^{19}$ (fig 1). Metabolism of vitamin A within these cells and subsequent transfer into the lymphatic system depends on a specific carrier protein, cellular retinol binding protein type 2 , the availability of which may be limited in the preterm infant. ${ }^{20}{ }^{21}$ After absorption, retinol is bound to RBP in the liver and transported in plasma as the retinol-RBP complex, bound in a $1: 1$ ratio with transthyretin. Circulating retinol is delivered to target tissues via a specific membrane receptor and is oxidised within the cell to its active metabolite, retinoic acid. The precise mechanisms by which retinoic acid affects intracellular activity are complex and incompletely defined. ${ }^{22}{ }^{23}$ Some $90 \%$ of the body's reserve of vitamin A is stored in the liver as retinyl esters; other sites of major vitamin A storage include the eye and the lung. In the retina, reversible oxidation of vitamin A produces a second active metabolite, retinaldehyde. Retinaldehyde is an essential constituent of the visual pigment rhodopsin, photoisomerisation of which induces a phototransduction cascade in response to light, the first stage in the process of vision.

Abbreviations: ELBW, extremely low birth weight; ERG electroretinogram; RBP, retinol binding protein; RDR, relative dose response; $R O P$, retinopathy of prematurity; VLBW, very low birth weight 


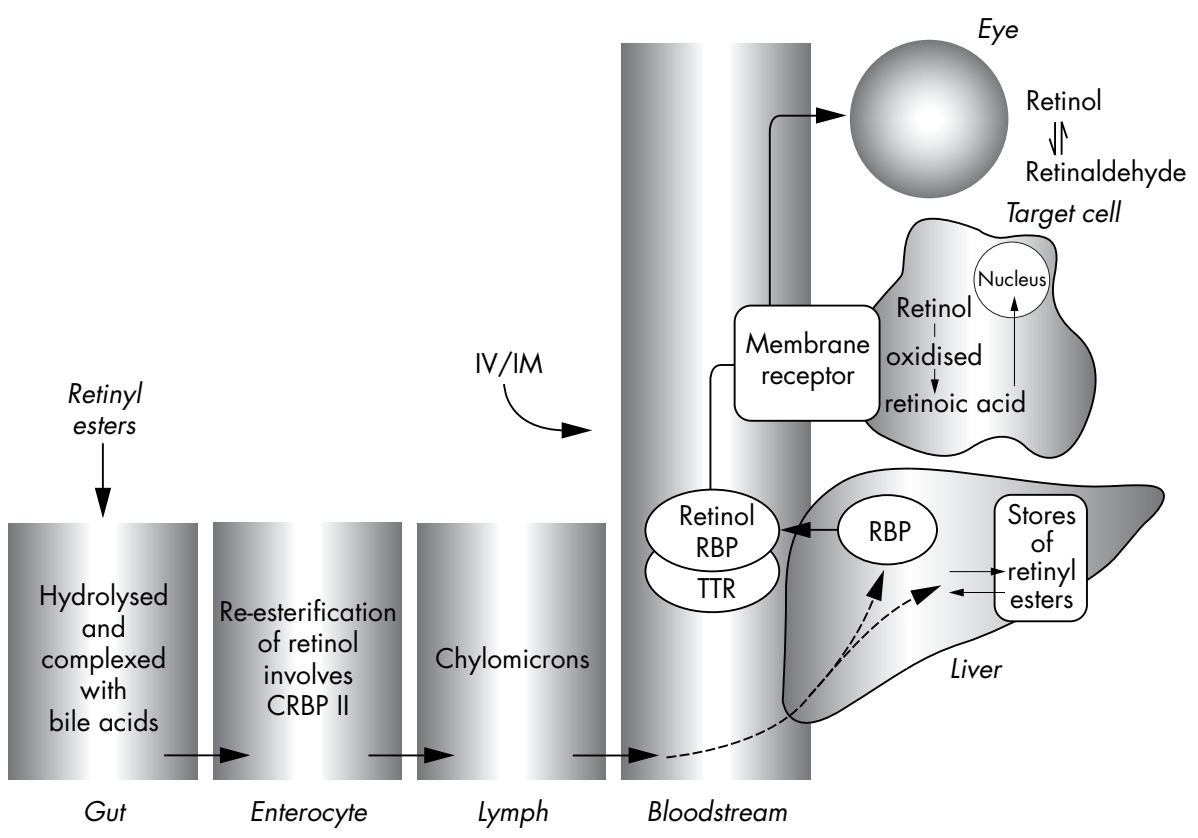

Figure 1 Uptake and metabolism of vitamin A. CRBP II, Cellular retinol binding protein type 2; IV, intravenous; $I M$, intramuscular; $R B P$, retinol binding protein; TTR, transthyretin.

\section{BIOLOGICAL EFFECTS OF VITAMIN A IN THE PRETERM INFANT \\ Respiratory function}

Vitamin A is required in the fetal lung for both cellular differentiation and surfactant synthesis. ${ }^{23}{ }^{24}$ In the rat, significant storage of vitamin A in the lungs occurs in the third trimester. These stores are rapidly depleted during late pregnancy and the early weeks of postnatal life as the lungs grow and develop. ${ }^{25}$ Vitamin A and steroid hormones have similar effects on prenatal and postnatal lung development, operate through similar cell receptors, and may be interdependent. ${ }^{23}$ The pathological changes of chronic lung disease are similar to those observed in vitamin A deficient experimental animals. ${ }^{26-28}$ Plasma retinol concentrations were lower ${ }^{11} 29-31$ and hepatic stores less ${ }^{15}{ }^{32} 33$ in preterm infants who developed bronchopulmonary dysplasia, supporting the hypothesis that vitamin A deficiency contributes to the development of chronic lung disease and/or respiratory tract infections in this population. ${ }^{30}{ }^{34}$ Observational and randomised studies of supplemental vitamin A produced conflicting results, attributable to a combination of factors, including small patient numbers, use of postnatal steroids, and variations in ventilatory management, baseline vitamin A status, and supplementation regimens. ${ }^{35-41}$ Tyson et $a l^{42}$ showed that giving intramuscular vitamin A to ELBW infants from day 2 lowers the risk of chronic lung disease at 36 corrected weeks, as well as reducing biochemical evidence of vitamin A deficiency. Thus there is a small, but significant reduction in death or oxygen dependency by 1 month of age in preterm infants supplemented with intramuscular vitamin A. $^{12}$

\section{Visual function}

Vitamin A is necessary for the health of the anterior eye and is also an essential constituent of visual pigment (and therefore the developing photoreceptors). Deficiency in older children and adults presents as xerophthalmia, signs and symptoms of which include night blindness, corneal ulcers, and keratomalacia. ${ }^{43}$ Microscopic conjunctival changes consistent with vitamin A deficiency have been noted in preterm babies, but the relation to vitamin A status was not explored. ${ }^{44}$ The preterm infant retina at birth contains several times less rhodopsin than at term birth ${ }^{45}$; how rapidly rhodopsin is subsequently accreted, and how this is related to total body stores of vitamin A, is not known. The rhodopsin content of the developing rat retina is dependent on vitamin A sufficiency and is reduced by early exposure to light. ${ }^{46}{ }^{47}$ Dark adapted (rod photoreceptor) retinal sensitivity is dependent on retinal vitamin A sufficiency, and impaired dark adaptation is one of the earliest manifestations of vitamin A deficiency. ${ }^{48-50}$ Rod photoreceptor sensitivity can be assessed electrophysiologically and correlates with subjective testing. ${ }^{51}$ Retinal sensitivity, as measured by the electroretinogram (ERG), increases dramatically between 30 and 50 postmenstrual weeks, ${ }^{52}{ }^{53}$ and preliminary data suggest that retinal sensitivity in preterm infants correlates with hepatic stores of vitamin A. ${ }^{54}$ Dark adapted retinal sensitivity is less in ex-preterm infants at term corrected age than in newborn term infants; the reason for this is not clear $^{55}$ (fig 2).

\section{Vitamin A and retinopathy of prematurity (ROP)}

Low plasma vitamin A concentrations have been associated in some studies with the development of ROP, ${ }^{11}{ }^{38}$ and abnormal conjunctival impression cytology (reflective of poor

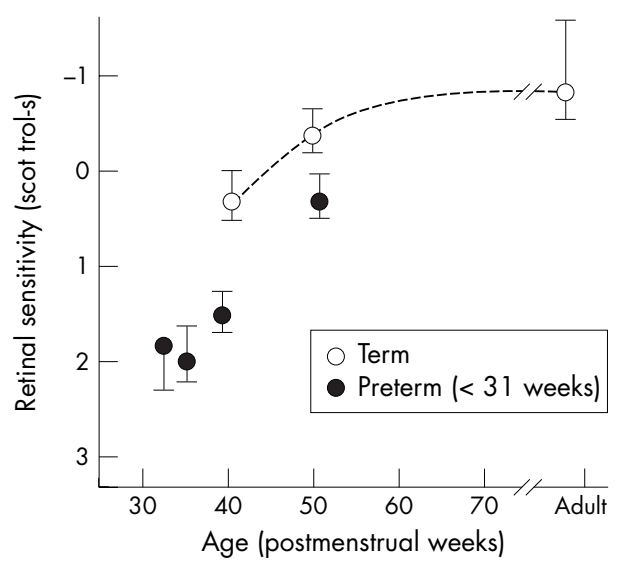

Figure 2 Increase in retinal sensitivity with age (retinal sensitivity defined as the retinal illuminance of the flash which produces a halfmaximal electroretinogram). 
retinol status in adults) has been associated with ROP requiring treatment. ${ }^{44}$ Pooled data show a non-significant trend towards a reduction in ROP in vitamin A supplemented infants. ${ }^{12}$ The pathogenesis of ROP is complex and includes free radical mediated oxidative damage to the developing retina which could in theory be ameliorated by the antioxidant properties of vitamin A. ${ }^{56}{ }^{57}$ ROP adversely affects the developing photoreceptors ${ }^{58} 59$; whether this is influenced by the availability of vitamin A and/or rhodopsin is unknown. The incidence of threshold ROP in a group of ELBW infants who received $10000 \mathrm{IU}$ intramuscular vitamin A three times a week was nil, compared with $16 \%$ in those who received half this dose. ${ }^{60}$ Although this result did not achieve statistical significance, it suggests that higher doses of vitamin A than those associated with improved respiratory outcome in preterm infants may have a beneficial effect on the incidence of ROP.

\section{Cardiovascular system}

Vitamin A is required in early gestation for normal cardiopulmonary development, and postnatally it accelerates the development of oxygen induced contraction of the ductus arteriosus in the rat model. ${ }^{61}$ In a small group of ventilator dependent preterm infants weighing 500-1500 g, intramuscular vitamin A did not affect the spontaneous closure rate of patent ductus arteriosus. The dose used was, however, less than that shown to improve respiratory outcome. ${ }^{62}$

\section{Immune competence}

There is some evidence that vitamin A supplementation reduces the risk of airway infection, ${ }^{38}$ and pooled data show a non-significant trend towards reduction of culture positive nosocomial sepsis in vitamin A supplemented infants. ${ }^{12}$

\section{Other effects}

The incidence and severity of intraventricular haemorrhage is higher in infants born with low hepatic stores of vitamin $\mathrm{A}^{.15}$ Postnatal vitamin A supplementation of ELBW infants was not, however, associated with a significant reduction in the incidence of intraventricular haemorrhage. ${ }^{42}$

\section{PLASMA CONCENTRATIONS OF VITAMIN A IN PRETERM INFANTS \\ Problems in interpretation}

In older human subjects and in animals, plasma concentrations of retinol are maintained at the expense of hepatic stores and reflect body stores only in states of critical depletion or excess. ${ }^{436364}$ In vitamin A deficient subjects, supplemental vitamin A may be used to produce clinical benefit without necessarily improving plasma concentrations or body stores. ${ }^{40}$ Furthermore, the pharmacokinetics of vitamin A are likely to vary between infants, and it is not clear whether the peak or trough plasma retinol value is more important in terms of vitamin A status. ${ }^{60}$ Plasma retinol may reflect the availability of its carrier protein, RBP, which is typically low in the preterm infant. ${ }^{10} 16$

\section{What is an acceptable plasma vitamin A concentration?}

Vitamin A sufficiency in older children and adults is defined as plasma concentrations in the range $0.7-2.8 \mu \mathrm{mol} / \mathrm{l}$. Plasma concentrations of retinol $<0.35 \mu \mathrm{mol} / \mathrm{l}(100 \mu \mathrm{g} / \mathrm{l})$ are associated with reduced hepatic stores, and clinical signs of vitamin A deficiency and are considered to indicate severe deficiency. ${ }^{64-66}$ Milder biochemical deficiency in childhood, although not manifest as xerophthalmia, is associated with increased morbidity and mortality. ${ }^{43}$ Studies of vitamin A supplementation in the preterm infant population suggest that plasma retinol concentrations $\geqslant 0.7 \mu \mathrm{mol} / \mathrm{l}$ indicate vitamin A sufficiency, ${ }^{38}{ }^{39}$ but these data were confounded by the use of postnatal steroids. Most even relatively healthy preterm infants have plasma retinol concentrations $<0.7 \mu \mathrm{mol} / \mathrm{l}$ throughout their stay in the neonatal unit, and $20 \%$ of ELBW babies who have not received intramuscular vitamin A have plasma retinol concentrations $<0.35 \mu \mathrm{mol} / \mathrm{l}$ at 28 days. ${ }^{11}{ }^{164267}$ The significance for preterm infants, in terms of functional vitamin A status, of low plasma concentrations of vitamin A is not, however, clear.

\section{Effects of corticosteroids}

Antenatal and postnatal corticosteroids significantly increase plasma concentrations of retinol in preterm infants. ${ }^{11}{ }^{1568-70}$ Administration of antenatal steroids may contribute to higher plasma values measured soon after birth in the most immature preterm infants (own observations). ${ }^{11}{ }^{16}$ In the rat model, the increase in serum retinol in response to steroids is at the expense of hepatic stores. ${ }^{71}$ Hepatic and pulmonary stores of vitamin A were increased in ELBW infants who had received postnatal corticosteroids, ${ }^{42}$ but numbers were small, and babies undergoing postmortem examination may not be representative of the population. It is likely that the beneficial pulmonary response to postnatal steroids may be mediated, at least in part, by vitamin A. ${ }^{23} 70$

\section{ASSESSMENT OF VITAMIN A STATUS IN PRETERM INFANTS}

Clearly therefore assessment of vitamin A status in preterm infants should include consideration of body stores as well as (or perhaps instead of) circulating concentrations of retinol.

\section{Liver}

Indirect measure of hepatic stores can be achieved in vivo by means of the relative dose response (RDR), and this test has been successfully applied to preterm infants. ${ }^{15} 323372$ Hepatocytes deficient in vitamin A rapidly take it up from the circulation after an oral or intramuscular dose, and secrete it as retinol complexed to RBP. ${ }^{73}$ Measurement of either retinol or RBP can be used to calculate the RDR. The $\mathrm{RDR}$ is the percentage difference between the predose plasma retinol or RBP concentration and the plasma concentration five hours after the dose. The test distinguishes between low plasma retinol concentrations due to vitamin A deficiency (high RDR) and low plasma retinol concentrations due to other factors (low RDR). In healthy preterm infants ready for discharge, the RDR correlates with the predose retinol concentration, suggesting that low plasma retinol concentrations in these preterm infants reflect reduced hepatic stores of vitamin A. ${ }^{32} 72$ Even when the plasma retinol concentration has been increased by intramuscular supplementation, the RDR may indicate reduced hepatic stores. ${ }^{32}$

\section{Eye}

Ocular stores of vitamin A influence both dark adapted retinal function and the health of the corneal epithelium. ERG provides objective assessment of retinal function and can be applied to preterm infants from 31 weeks after conception. ${ }^{52-55} 74$ Changes in the dark adapted ERG are present in adults and children with vitamin A deficiency and may be a more accurate reflection of vitamin A status than plasma retinol..$^{75}$ Except in the most severe cases, ERG changes can be reversed with vitamin A supplementation. ${ }^{76} 77$ In animal studies, both the dark adapted ERG threshold and the amplitude of the ERG reflect retinal vitamin A status. ${ }^{63} 78$ Reduced retinal sensitivity in preterm infants at term corrected age may reflect vitamin A deficiency, although other confounding effects of preterm birth on the developing retina have not been studied in detail. The long term consequences, if any, are unknown. Conjunctival impression cytology has been used to assess vitamin A status in adults ${ }^{79}$ and can be easily incorporated into ROP screening ${ }^{44}$; its 
relation to vitamin A status in the preterm infant has, however, not yet been fully explored.

\section{Lungs}

Pulmonary stores of vitamin A in preterm infants cannot, of course, be measured in vivo, and postmortem data may not reflect the situation in life. The preterm human infant's lungs may be deficient in vitamin A at birth, but whether this can be modified by supplementation of either mother or newborn infant is unknown. We do not know how lung concentrations of vitamin A relate (if at all) to either plasma retinol or RDR. Intramuscular supplementation did not significantly increase pulmonary stores of vitamin A in a small group of ELBW infants. $^{42}$ Animal and adult human studies have shown increased vitamin A consumption and depletion of hepatic stores in inflammatory disease of the lungs. ${ }^{80} 81$ Currently unanswerable questions include whether low pulmonary stores of vitamin A reflect deficiency or increased use, and whether use of vitamin A in the developing lungs of the preterm infant is limited only by supply.

\section{VITAMIN A SUPPLEMENTATION}

Vitamin A can be given enterally, intramuscularly, or intravenously. In term infants, vitamin A is well absorbed enterally (except in malabsorptive states), and supplemental vitamin $\mathrm{A}$ is given enterally to infants and children of all ages. In very low birth weight (VLBW) infants, vitamin A given orally in conjunction with early feeds can achieve comparable plasma concentrations of retinol to vitamin A given intramuscularly if sufficiently generous oral doses are given. ${ }^{82}$ In ELBW infants, however, even very large enteral doses of vitamin A from birth do not significantly increase plasma concentrations of vitamin A or improve outcome. ${ }^{83} 84$ Given that these are the very infants most likely to benefit from additional vitamin A, they must be supplemented by a parenteral route, at least in the early days of life.

Intravenous administration of vitamin $\mathrm{A}$ is problematic. Vitamin A degrades in light, and there is significant adsorption to the tubing. ${ }^{85}$ Mixing vitamin A with lipid emulsion before infusion increases efficacy of delivery, ${ }^{86}$ and this is the recommended method of intravenous administration. The practice of delivering a multivitamin preparation in an amino acid/dextrose mix, as still occurs commonly outwith the United Kingdom, is strongly to be discouraged. In the United Kingdom, supplementary vitamin $\mathrm{A}$ is generally given as Vitlipid N (Fresenius Kabi Ltd, Runcorn, Cheshire, UK), at a recommended dose of $4 \mathrm{ml} / \mathrm{kg} /$ day. This provides $910 \mathrm{IU} / \mathrm{kg} / \mathrm{day}(280 \mu \mathrm{g} / \mathrm{kg} /$ day $)$ vitamin A in addition to vitamins $\mathrm{D}, \mathrm{E}$, and $\mathrm{K}$, equivalent to the approximate daily retinol intake of a term, breast fed infant of a well nourished mother during the first week of life. ${ }^{87}$ Although this dose increased the mean plasma retinol in seven VLBW infants, the plasma retinol concentration was not consistently maintained above $0.7 \mu \mathrm{mol} / 1 .^{88}$ The American Society for Clinical Nutrition subsequently recommended $910 \mathrm{IU} / \mathrm{kg} /$ day as the minimum dose suitable for preterm infants, and suggested evaluation of a higher dose. ${ }^{89}$ Increasing the vitamin A content of intravenous fat emulsion by two to threefold (total vitamin A intake 2700 IU/day) increased mean plasma retinol in a group of VLBW infants, although no difference in clinical outcome was noted. ${ }^{90}$ Infants were not all at significant risk of bronchopulmonary dysplasia, however, and numbers were small. Pilot data from our unit suggest that the currently recommended intravenous dose of supplemental vitamin A does not improve plasma concentrations of vitamin A in VLBW infants. ${ }^{67}$

The optimal intramuscular dose is similarly unclear. To increase serum retinol concentrations, the minimum effective dose in ELBW infants is of the order of 5000 IU three times a week. ${ }^{84}$ This regimen improves respiratory outcome in ELBW infants, but considerable numbers of treated infants still have borderline plasma retinol concentrations and biochemical evidence of low hepatic stores. ${ }^{42}$ Doubling this dose did not significantly increase mean plasma retinol in ELBW infants nor improve hepatic stores; there was, however, a wide range of plasma retinol concentrations within the treatment groups. ${ }^{60}$ Intramuscular administration is painful, and the justification of giving 12 injections to every ELBW infant for modest improvement in short term respiratory outcome has been questioned. ${ }^{91}$ Despite evidence of benefit, intramuscular supplementation of vitamin A is not widely practised, even in the United States. ${ }^{92}$ Intramuscular injections once a week are associated with worse biochemical vitamin A status than the same dose of vitamin $\mathrm{A}$ in divided doses three times a week. ${ }^{60}$ For the smallest, sickest infants, parenteral administration of vitamin $\mathrm{A}$ is more efficacious than enteral administration, but it is not clear how intravenous administration of vitamin A in lipid emulsion compares with intramuscular administration. No published study to date has directly compared intramuscular with intravenous administration of vitamin A in VLBW infants, in terms of morbidity, mortality, or vitamin A status.

Most neonatal units administer oral vitamin supplements to preterm infants once enteral feeding has been established, but doses vary and are not generally adjusted in favour of the smallest, most immature infants. Many neonatologists will not be aware that the vitamin A content of ABIDEC (Pfizer Ltd, Walton Oaks, UK) has been reduced by two thirds so that the recommended dose of $0.3 \mathrm{ml}$ daily provides only $666 \mathrm{IU}$ retinol. A further $550 \mathrm{IU}$ retinol is provided by $180 \mathrm{ml}$ low birthweight infant formula (Wyeth Pharmaceuticals, Maidenhead, UK). Oral supplementation of $4000 \mathrm{IU} / \mathrm{kg} /$ day has been recommended for VLBW infants from establishment of full enteral feeding until discharge from the neonatal unit, ${ }^{93}$ and the Canadian government has recently approved increased vitamin A in preterm formulae, up to 1420 IU per $100 \mathrm{kcal}$ (equivalent to about $2100 \mathrm{IU}$ per $180 \mathrm{ml}$ ). ${ }^{94}$

Inhalation of vitamin $\mathrm{A}$ in aerosol improved biochemical vitamin A status in a small group of preschool children in Ethiopia. ${ }^{95}$ This novel method of administration has not yet been explored in infants.

\section{VITAMIN A TOXICITY}

Concerns about the potential toxicity of vitamin A have led to caution in the doses administered to preterm infants, but appear to be largely unfounded. There is no published evidence to suggest that parenteral supplemental vitamin A in preterm infants in doses of up to $8500 \mathrm{IU} / \mathrm{kg} /$ day is associated with significant side effects. ${ }^{41}{ }^{42}{ }^{60}$ Neonatal vitamin A supplementation of larger infants is not associated with any adverse developmental sequelae, even when associated with bulging fontanelle..$^{969}$

\section{CONCLUSIONS}

More than 20 years after it was first recognised that preterm infants may be functionally deficient in vitamin A, we still do not know how much to give, or by which route. There are considerable differences in clinical practice between North America and the United Kingdom. The smallest and sickest infants in our care are at highest risk of suffering from the sequelae of vitamin A deficiency, and it is increasingly clear that they should receive parenteral supplemental vitamin A within the first few days of life, and probably from day 1. Once enteral feeding is established, oral supplementation is preferred, but currently administered doses may be inadequate for VLBW preterm infants. To define optimal intake and mode of delivery of vitamin A, we need good quality research which includes quantification of hepatic stores as 
well as assessment of retinal function and long term clinical outcome. Measuring plasma concentrations of retinol is not sufficient to assess vitamin A status properly in preterm infants. There is an urgent need for a comparison of the efficacy of intramuscular and intravenous administration and a review of the current practice of intravenous supplementation. Vitamin A supplementation of term born infants in developing countries has proved to be enormously beneficial and cost effective. The time has come to ensure that the most vulnerable infants in our own society are also given appropriate amounts of this essential micronutrient during the critical early weeks of life.

\section{ACKNOWLEDGEMENTS}

We thank Ruth Hamilton for helpful comments during the preparation of this manuscript, and for providing fig 2. Fig 1 was drawn by Jean Hyslop.

\section{Authors' affiliations}

H Mactier, Princess Royal Maternity and Division of Developmental Medicine, University of Glasgow, Glasgow, Scotland, UK

L T Weaver, Division of Developmental Medicine, University of Glasgow, Royal Hospital for Sick Children, Yorkhill, Glasgow G3 8SJ

Competing interests: none declared

\section{REFERENCES}

1 Hopkins FG. Feeding experiments illustrating the importance of accessory factors in normal dietaries. J Physiol 1912;44:425-60.

2 McCollum EV, Davis M. The influence of certain vegetable fats on growth. J Biol Chem 1915;21:179-82.

3 Humphrey JH, Agoestina T, Wu L, et al. Impact of neonatal vitamin A supplementation on infant morbidity and mortality. J Pediatr 1996;128:489-96.

4 Roy SK, Islam A, Molla A, et al. Impact of a single megadose of vitamin A at delivery on breastmilk of mothers and morbidity of their infants. Eur J Clin Nutr 1997; $51: 302-7$

5 Haidar J, Tsegaye D, Maiam DH, et al. Vitamin A supplementation on child morbidity. E Afr Med J 2003;80:17-21.

6 Rahmathallah L, Tielsch JM, Thulasiraj RD, et al. Impact of supplementing newborn infants with vitamin A on early infant mortality: community based randomized trial in southern India. BMJ 2003;327:254-7.

7 World Bank. The World Bank world development report 1993: investing in health. Oxford: Oxford University Press, 1993.

8 Humphrey JH, Rice AL. Vitamin A supplementation of young infants. Lancet 2000;356:422-4.

9 Brandt RB, Mueller DG, Schroeder JR, et al. Serum vitamin A in premature and term neonates. J Pediatr 1978;92:101-4.

10 Shenai JP, Chytil F, Jhaveri A, et al. Plasma vitamin A and retinol-binding protein in preterm and term neonates. J Pediatr 1981;99:302-5

11 Inder TE, Graham PJ, Winterbourn CC, et al. Plasma vitamin A levels in the very low birthweight infant: relationship to respiratory outcome. Early Hum Dev 1998;52:155-68.

12 Darlow BA, Graham PJ. Vitamin A supplementation for preventing morbidity and mortality in very low birthweight infants (Cochrane Review). Cochrane Library. Issue 3. Oxford: Update Software, 2003.

13 Olson JA, Gunning DB, Tilton RA. Liver concentrations of vitamin A and carotenoids, as a function of age and other parameters, of American children who died of various causes. Am J Clin Nutr 1984;39:903-10.

14 Shenai JP, Chytil F, Stahlman MT. Liver vitamin A reserves of very low birth weight neonates. Pediatr Res 1985;19:892-93.

15 Zachman RD, Samuels DP, Brand JM, et al. Use of the intramuscular relativedose-response test to predict bronchopulmonary dysplasia in premature infants. Am J Clin Nutr 1996;63:123-9.

16 Woodruff CW, Latham CB, James EP, et al. Vitamin A status of preterm infants: the influence of feeding and vitamin supplements. Am J Clin Nutr 1982;44:384-9.

17 Peeples JM, Carlson SE, Werkmen SH, et al. Vitamin-A status of preterm infants during infancy. Am J Clin Nutr 1991:53:1455-9.

18 Tammela O, Aitola M, Ikonen S. Cord blood concentrations of vitamin A in preterm infants. Early Hum Dev 1999;56:39-47.

19 Shenai JP. Vitamin A. In: Tsang RC, Lucas A, Uauy R, et al, eds. Nutritional needs of the preterm infant: scientific basis and practical guidelines. Baltimore: Williams and Williams, 1993:87-100.

20 Ong DE. A novel retinol-binding protein from rat: purification and partial characterization. J Biol Chem 1984;259:1476-82.

21 Ong DE, Page DL. Cellular retinol-binding protein (type two) is abundant in human small intestine. J Lipid Res 1987;28:739-45.

22 Perrotta S, Nobili B, Rossi F, et al. Vitamin A and infancy. Biochemical, functional and clinical aspects. Vitam Horm 2003;66:457-591.

23 Biesalski HK, Nohr I. Importance of vitamin-A for lung function and development. Mol Aspects Med 2003;24:431-40.
24 Metzler MD, Snyder JM. Retinoic acid differentially regulates expression of surfactant associated proteins in human fetal lung. Endocrinology 1993; 133:1990-8.

25 Shenai JP, Chytil F. Vitamin A storage in lungs during perinatal development in the rat. Biol Neonate 1990;57:126-32.

26 Blackfan KD, Wolbach SB. Vitamin A deficiency in infants: a clinical and pathological study. J Pediatr 1933;3:679-706

27 Northway WH, Rosan RC, Porter DY. Pulmonary disease following respirator therapy of hyaline-membrane disease-bronchopulmonary dysplasia. N Engl J Med 1967;276:357.

28 Chytil F. The lungs and vitamin A. Am J Physiol 1992;262:1517-27.

29 Hustead VA, Gutcher GR, Anderson SA, et al. Relationship of vitamin A (retinol) status to lung disease in the preterm infant. J Pediatr 1984;105:610-11.

30 Shenai JP, Chytil F, Stahlman MT. Vitamin A status of neonates with bronchopulmonary dysplasia. Pediatr Res 1985;19:185-8.

31 Verma RP, McCulloch KM, Worrell L, et al. Vitamin A deficiency and severe bronchopulmonary dysplasia in very low birthweight infants. Am J Perinatol 1996;13:389-93.

32 Shenai JP, Rush MG, Stahlman MT, et al. Plasma retinol-binding protein response to vitamin A administration in infants susceptible to bronchopulmonary dysplasia. J Pediatr 1990;1 16:607-14.

33 Shenai JP, Rush M, Parker RA, et al. Sequential evaluation of plasma retinolbinding protein response to vitamin A administration in very-low-birth-weight neonates. Biochem Mol Med 1995;54:67-74.

34 Bancalari E, Claure N, Sosenko IR. Bronchopulmonary dysplasia: changes in pathogenesis, epidemiology and definition. Semin Perinatol 2003;8:63-71.

35 Chabra S, Arnold JD, Leslie Gl, et al. Vitamin A status in preterm neonates with and without chronic lung disease. J Paediatr Child Health 1994;30:432-5.

36 Chan V, Greenough A, Cheeseman P, et al. Vitamin A levels at birth of high risk preterm infants. J Perinatal Med 1993;21:147-51.

37 Bonati M. Supplementation and plasma levels of vitamin A in premature newborns at risk for chronic lung disease. Dev Pharmacol Ther 1993;20: 144-51

38 Shenai JP, Kennedy KA, Chytil F, et al. Clinical trial of vitamin A supplementation in infants susceptible to bronchopulmonary dysplasia. J Pediatr 1987;111:269-77.

39 Pearson E, Bose C, Snidow T, et al. Trial of vitamin A supplementation in very low birth weight infants at risk of bronchopulmonary dysplasia. J Pediatr 1992;121:420-7.

40 Robbins ST, Fletcher AB. Early vs delayed vitamin A supplementation in verylow-birth-weight infants. J Parenteral Ent Nutr 1993;17:220-5.

41 Coutsoudis A, Adhikari M, Pillay K, et al. Effect of vitamin A supplementation on morbidity of low-birthweight infants. S Afr Med J 2000;90:730-6.

42 Tyson JE, Wright LL, Oh W, et al. Vitamin A supplementation for extremelylow-birth-weight infants. N Engl J Med 1999;340:1962-8.

43 Sommer A, West KP, eds. Vitamin A deficiency: health, survival and vision. Oxford: Oxford University Press, 1996.

44 Hughes AP, Shaw NJ, Southall P, et al. Conjunctival impression cytology in the preterm infant and its relation to outcome. Eur J Pediatr 1997;156:471-5.

45 Fulton AB, Dodge J, Hansen RM, et al. The rhodopsin content of human eyes. Invest Ophthalmol Vis Sci 1999;40:1878-83.

46 Noell WK, Delmelle MC, Albrecht R. Vitamin A deficiency effect on retina: dependence on light. Science 1971;172:72-5.

47 Katz ML, Steinties HJ, Norberg M. Bright environmental light accelerates rhodopsin depletion in retinoid-deprived rats. Invest Ophthalmol Vis Sci 1993;34:2000-8

48 Wald G, Jeghers H, Arminio J. An experiment in human dietary nightblindness. Am J Physiol 1938;123:732-46.

49 Fulton AB, Manning KA, Baker BN, et al. Dark-adapted sensitivity, rhodopsin content, and background adaptation in pcd/pcd mice. Invest Ophthalmol Vis Sci 1982;22:386-93.

50 Fulton AB, Hansen RM, Underwood BA, et al. Scotopic thresholds and plasma retinol in cystic fibrosis. Invest Ophthalmol Vis Sci 1982;23:364-70.

51 Fulton AB, Hansen RM. The development of scotopic sensitivity. Invest Ophthalmol Vis Sci 2000;41:1588-96.

52 Mactier $\mathrm{H}$, Hamilton R, Bradnam MS, et al. Contact lens electroretinography in preterm infants from 32 weeks after conception: a development in current methodology. Arch Dis Child Fetal Neonatal Ed 2000;82:F233-6.

53 Hamilton R, Bradnam MS, Dudgeon J, et al. Development of the electroretinogram (ERG) between 30 and 50 weeks after conception: a case study. Early Hum Dev 2005; in press.

54 Mactier $\mathrm{H}$. The electroretinogram and vitamin $\mathrm{A}$ in preterm infants. MD thesis. Glasgow, 1988.

55 Hamilton R, Mactier H, Malcolm C, et al. Rod electroretinograms (ERGs) in infants with treated retinopathy of prematurity [abstract]. Presented at ARVO, Florida, May 2002.

56 Rao NA, Wu GS. Oxygen free radicals and retinopathy of prematurity. Br J Ophthalmol 1996;80:387.

57 Schwarz KB, Cox JM, Sharma S, et al. Possible antioxidant effect of vitamin A supplementation in premature infants. J Pediatr Gastroenterol Nutr 1997;25:408-14.

58 Fulton AB, Reynaud X, Hansen RM, et al. Rod photoreceptors in infant rats with a history of oxygen exposure. Invest Ophthalmol Vis Sci 1999:40:168-74.

59 Fulton $A B$, Hansen RM. Photoreceptor function in infants and children with a history of mild retinopathy of prematurity. J Opt Soc Am 1996;13:566-71.

60 Ambalavanan N, Wu T-J, Tyson J, et al. A comparison of three vitamin A dosing regimes in extremely-low-birth-weight infants. J Pediatr 2003;142:656-61. 
61 Shaul PW. Maternal vitamin A administration and the fetal ductus arteriosus: commentary on the article by Wu et al on page 747. Pediatr Res $2001 ; 49: 744-6$.

62 Ravishankar C, Nafday S, Green RS, et al. A trial of vitamin A therapy to facilitate ductal closure in premature infants. J Pediatr 2003;143:644-8.

63 Dowling JE, Wald G. Vitamin A deficiency and night blindness. Proc Natl Acad Sci USA 1958;44:648-61

64 Pitt GAJ. The assessment of vitamin A status. Proc Nutr Soc 1981;40:173-8.

65 Underwood BA. Vitamin A in animal and human nutrition. In: Sporn MB, Roberts AB, Goodman DS, eds. The retinoids. Orlando, FL: Academic Press, 1984:282-392.

66 US Department of Health, Education and Welfare. Guidelines for classification and interpretation of group blood and urine data collected as part of the National Nutrition Survey. Pediatr Res 1970;4:103.

67 Mactier H, Galloway P, Hamilton R, et al. Inadequacy of IV vitamin A supplementation of extremely preterm infants? [Letter] $J$ Pediatr 2005; in press.

68 Georgieff MK, Mamel MC, Mills MM, et al. Effect of postnatal steroid administration on serum vitamin A concentrations in newborn infants with respiratory compromise. J Pediatr 1987;114:301-4.

69 Georgieff MK, Chockalingham UM, Sasanow SR, et al. The effect of antenatal betamethasone on cord blood concentrations of retinol-binding protein, transthyretin, transferrin, retinol and vitamin E. J Pediatr Gastroenterol Nutr 1998;7:713-17.

70 Shenai J, Mellen BG, Chytil F. Vitamin A status and postnatal dexamethasone treatment in bronchopulmonary dysplasia. Pediatrics 2000;106:547-53.

71 Georgieff MK, Radmer WJ, Sowell AL, et al. The effect of glucocorticoids on serum, liver, and lung vitamin A and retinyl ester concentrations. J Pediatr Gastroenterol Nutr 1991;13:376-82.

72 Woodruff CW, Latham CB, Mactier $\mathrm{H}$, et al. Vitamin A status of preterm infants: the correlation between plasma retinol concentration and retinol dose response. Am J Clin Nutr 1987:46:985-8.

73 Loerch JD, Underwood BA, Lewis KC. Response of plasma levels of vitamin A to a dose of vitamin $A$ as an indicator of vitamin A reserves in rats. J Nutr 1979;109:778-86.

74 Grose J, Harding GFA, Wilton AY, et al. The maturation of the pattern reversal VEP and flash ERG in preterm infants. Clin Vis Sci 1989;4:239-46.

75 Dhanda RP. Electroretinography in night blindness and other vitamin-A deficiencies. AMA Arch Ophthalmol 1955;54:841-9.

76 Genest AA, Sarwono D, Gyorgy P. Vitamin A blood serum levels and electroretinogram in 5- to 14-year age group in Indonesia and Thailand. 1967;20:1275-9.

77 Bors F, Fells P. Reversal of the complications of self-induced vitamin A deficiency. Br J Ophthalmol 1971;55:210-14

78 Dowling JE, Wald G. The biological function of vitamin A acid. Proc Natl Acad Sci USA 1960;46:587-608.

79 Wittpenn JR, Tseng S, Sommer A. Detection of early xerophthalmia by impression cytology. Arch Ophthalmol 1988;104:237-9.

80 Shoseyov D, Bibi H, Hans MD, et al. Repeated allergen challenge in rats increases vitamin A consumption. Chest 2002;122:1407-11.
81 Paiva SA, Godoy I, Vannuchi H, et al. Assessment of vitamin A status in chronic obstructive pulmonary disease patients and healthy controls. Am J Clin Nutr 1996;64:928-34.

82 Landman J, Sive A, De $\vee$ Hesse $H$, et al. Comparison of enteral and intramuscular vitamin A supplementation in preterm infants. Early Hum Dev 1992;39:163-70.

83 Wardle SP, Hughes A, Chen S, et al. Randomised controlled trial of oral vitamin A supplementation in preterm infants to prevent chronic lung disease. Arch Dis Child Fetal Neonatal Ed $2001 ; 84$ :F9-13.

84 Kennedy KA, Stoll BJ, Ehrenkranz RA, et al. Vitamin A to prevent bronchopulmonary dysplasia in very-low-birth-weight infants: has the dose been too low? Early Hum Dev 1997;49:19-31.

85 Haas C, Genzel-Boroviczeny O, Koletko B. Losses of vitamin A and E in parenteral nutrition suitable for premature infants. Eur J Clin Nutr 2002;56:942-6.

86 Greene HL, Phillips BL, Franck L, et al. Persistently low blood retinol levels during and after parenteral administration of very low birth weight infants: examination of losses into intravenous administration sets and a method of prevention by addition to a lipid emulsion. Pediatrics 1987:79:894-900.

87 Zachman RD. Retinol (vitamin A) and the neonate: special problems of the human preterm infant. Am J Clin Nutr 1989;50:413-24.

88 Baeckert PA, Greene HL, Oelberg DG, et al. Vitamin concentrations in very low birth weight infants given vitamins intravenously in a lipid emulsion: measurement of vitamins $A, D$, and $E$ and riboflavin. J Pediatr 1988; 113:1057-65.

89 Greene HL, Hambridge KM, Schandler RJ, et al. Guidelines for the use of vitamins, trace elements, calcium, magnesium and phosphorus in infants and children receiving total parenteral nutrition: report of Subcommittee on Pediatric Parenteral Nutrient Requirements from the Committee on Clinical Practice Issues of the American Society for Clinical Nutrition. Am J Clin Nutr 1988;48:1324-42.

90 Werkman SH, Peeples JM, Cooke RJ, et al. Effect of vitamin A supplementation of intravenous lipids on vitamin $A$ intake and status of premature infants. Am J Clin Nutr 1994;59:586-92.

91 Bental YA, Rotschild A, Cooper PA. Vitamin A supplementation for extremelylow-birth-weight infants [letter]. N Engl J Med 1999;341:1697-8.

92 Ambalavanan N, Kennedy K, Tyson J, et al. Survey of vitamin A supplementation for extremely-low-birth-weight infants: is clinical practice consistent with the evidence? J Pediatr 2004;145:304-7.

93 Shenai JP. Vitamin A supplementation in very low birth weight neonates: rationale and evidence. Pediatrics 1999;104:1369-74

94 Gorman DC. Government notice: interim marketing authorization. January 2003 available at www.hc-sc.ca.

95 Biesalski HK. Effects of intratracheal application of vitamin A on concentrations of retinol derivates in plasma, lungs and selected tissue of rats. Int J Vit Nutr Res 1996;66:106-12.

96 Humphrey JH, Agoestina T, Juliana A, et al. Neonatal vitamin A supplementation: effect on development and growth at $3 y$ of age. Am J Clin Nutr 1998;68:109-17.

97 Illiff PJ, Humphrey JH, Mahomva Al, et al. Tolerance of large doses of vitamin A given to mothers and their babies shortly after delivery. Nutr Res 1999:19:1437-46.

\section{Register now!}

10th European Forum on Quality Improvement in Health Care

13-15 April 2005, ExCel Conference Centre, London

For further information on how to register please go to:

http://www.quality.bmipg.com 